\title{
Vibration and Performance Analyses Using Individual Blade Pitch Controls for Lift-Offset Rotors
}

\author{
Jae-Sang Park $\left(\mathbb{D},{ }^{1}\right.$ Do-Hyung Kim $\mathbb{D}^{2},{ }^{2}$ Sanghyun Chae, ${ }^{2}$ Ye-Lin Lee, ${ }^{1}$ and Jeong-In Go ${ }^{3}$ \\ ${ }^{1}$ Department of Aerospace Engineering, Chungnam National University, Daejeon 34134, Republic of Korea \\ ${ }^{2}$ Aircraft System Division, Korea Aerospace Research Institute, Daejeon 34133, Republic of Korea \\ ${ }^{3}$ Aeronautical Technology Directorate, Agency for Defense Development, Daejeon 34060, Republic of Korea
}

Correspondence should be addressed to Jae-Sang Park; aerotor@cnu.ac.kr

Received 11 August 2018; Revised 25 February 2019; Accepted 6 March 2019; Published 5 May 2019

Academic Editor: Joseph Majdalani

Copyright (c) 2019 Jae-Sang Park et al. This is an open access article distributed under the Creative Commons Attribution License, which permits unrestricted use, distribution, and reproduction in any medium, provided the original work is properly cited.

This work attempts to reduce the hub vibratory loads of a lift-offset rotor using IBC (individual blade pitch control) in high-speed forward flight. As a lift-offset rotor for the present study, the rigid coaxial rotor of a XH-59A compound helicopter is considered and CAMRAD II is used to predict the hub vibration and rotor performance. Using the IBC with a single harmonic input at 200 knots, the vibration index of the XH-59A rotor is minimized by about $62 \%$ when the $3 /$ rev actuation frequency is applied with the IBC amplitude of $1^{\circ}$ and control phase angle of $270^{\circ}\left(3 P / 1^{\circ} / 270^{\circ}\right)$; however, the rotor effective lift-to-drag ratio decreases by $3.43 \%$. When the $2 / \mathrm{rev}$ actuation frequency with the amplitude of $2^{\circ}$ and control phase angle of $270^{\circ}\left(2 P / 2^{\circ} / 270^{\circ}\right)$ and the $3 / \mathrm{rev}$ actuation frequency using the magnitude of $1^{\circ}$ and control phase angle of $210^{\circ}\left(3 P / 1^{\circ} / 210^{\circ}\right)$ are used in combination for the IBC with multiple harmonic inputs, the vibration index is reduced by about $62 \%$, while the rotor effective lift-to-drag ratio increases by $0.37 \%$ at a flight speed of 200 knots. This study shows that the hub vibration of the lift-offset rotor in high-speed flight can be reduced significantly but the rotor performance increases slightly, using the IBC with multiple harmonic inputs.

\section{Introduction}

Lift-offset helicopters using $\mathrm{ABC}^{\mathrm{TM}}$ (Advancing Blade Concept, [1]) have been developed to solve the low-speed flight performance of conventional helicopters. As seen in Figure $1[2,3]$, the lift-offset helicopter uses a counterrotating rigid coaxial rotor. Since most lift is generated by the advancing blades, the lift-offset rotor can avoid the dynamic stall on the retreating side of a rotor and may produce more lift as compared to a conventional helicopter rotor. Therefore, the rotation speed of the lift-offset rotor can be reduced moderately and high-speed flight is possible with the help of auxiliary propulsions [4].

Although lift-offset compound helicopters have showed excellent high-speed flight performance, they have a serious vibration problem during high-speed flights. In flight tests of the XH-59A compound helicopter, significant $3 / \mathrm{rev}$ cockpit vibration was observed because of the use of a rigid coaxial rotor and the absence of a vibration control system [5]. To solve this vibration problem in high-speed flights, the X2
Technology Demonstrator and S-97 Raider apply the AVCS (active vibration control system, [6]) to their airframes. The AVCS consists of accelerometers and circular force generators with electric motors and eccentric masses. The X2 Technology Demonstrator using the AVCS reduced the 4/rev cockpit vibration significantly in high-speed flights [7]. The AVCS can successfully alleviate the airframe vibration of lift-offset helicopters; however, it cannot reduce the vibration of a rigid coaxial rotor, which is the main source of vibration for the lift-offset helicopter. Therefore, the high levels of rotor vibration may still lead to serious constraints such as a restricted flight envelope, low fatigue life of the structural components, and a resultant high operating cost.

There have been numerous experimental and numerical works on active rotor controls such as HHC (higher harmonics pitch control, [8-11]), IBC (individual blade pitch control, [12-15]), active trailing-edge flap rotor [16-20], and active twist rotor [21-23] in order to reduce the rotor vibration of conventional helicopters. These active rotor controls usually excite the fixed or rotating system of a rotor with 


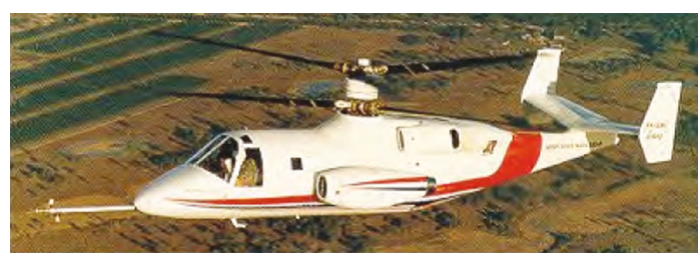

(a) XH-59A Technology Demonstrator [2]

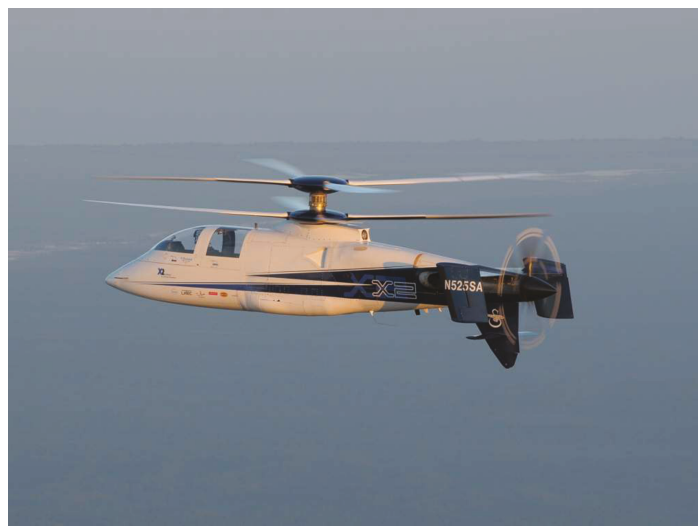

(b) X2 Technology Demonstrator [2]

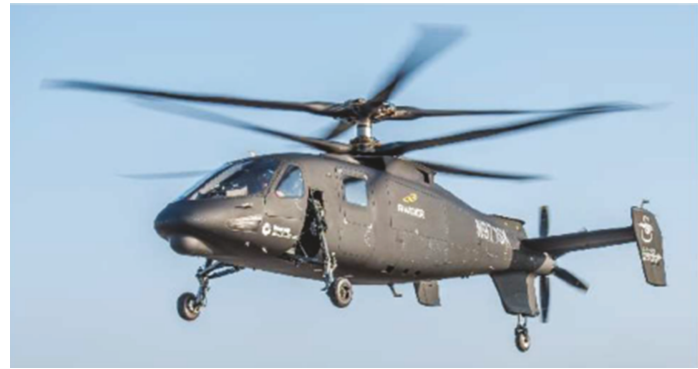

(c) S-97 Raider [3]

FIgure 1: Lift-offset helicopters using $\mathrm{ABC}^{\mathrm{TM}}$.

a single higher harmonic input to modify directly the periodic aerodynamic loads acting on the rotor blades for vibration reduction. The HHC demonstrated successfully the vibration reduction of full- and small-scale rotors of helicopters in flight tests $[8,9]$ and wind tunnel tests $[10,11]$, but the available actuation frequency range is limited since actuators are located below the swashplate. The IBC was developed to overcome the actuation frequency limitation of HHC. Since IBC uses the pitch link actuators in the rotating frame, each blade can be individually actuated and it has a wide range of actuation frequency. Using this advantage over HHC, IBC showed excellent vibration reduction capability for the full-scale rotors in wind tunnel tests $[12,13]$ and flight tests $[14,15]$. The vibration of helicopter rotors can be reduced significantly using the active trailing-edge flap in the advanced numerical analyses [16, 17], wind tunnel tests $[18,19]$, and flight tests $[20]$ while the power required to actuate flaps is approximately an order of magnitude less than the power required for the HHC and IBC systems. The ATR using piezoelectric fiber composites such as AFC (active fiber composites) and MFC (macro fiber composites) in wind tunnel tests and numerical analyses $[21,22]$ reduced significantly the vibratory loads of small-scale rotors. Recently, the International Cooperative Program, STAR (Smart-Twisting Active Rotor), has a plan to conduct the wind tunnel test in DNW (German-Dutch Wind Tunnels) using a scale rotor incorporating MFC actuators to investigate the vibration reduction [23]. In addition, there have been other active rotor controls such as the SHARCS (smart hybrid active rotor control system, [24]) with the smart spring and the active gurney flap [25] to alleviate vibratory loads of helicopter rotors. Although the extensive works using active vibration control techniques [8-25] have been conducted for conventional helicopter rotors as described above, there is only one research using the active rotor control to reduce the vibration of the lift-offset rotor [26]. In this work [26], HHC was applied to both the upper and lower rotors to reduce the vibration of the $\mathrm{XH}-59 \mathrm{~A}$ rotor. Although the $\mathrm{HHC}$ in the numerical analysis could significantly reduce the vibration of the XH-59A rotor in high-speed flights, the actuation frequency of the HHC is restricted as the $\left(N_{b}-1\right)$, $N_{\mathrm{b}}$, and $\left(N_{\mathrm{b}}+1\right) / \mathrm{rev}$ frequency. In addition, the rotor performance was not investigated when HHC was used to reduce the vibration of the $\mathrm{XH}-59 \mathrm{~A}$ lift-offset rotor. It is known that it is not easy to obtain rotor vibration reduction and rotor performance improvement simultaneously by using active rotor control with a single harmonic input [13].

There are limited works on vibration analyses of the liftoffset rotor using rotorcraft comprehensive analyses [26-28]. The RCAS (rotorcraft comprehensive analysis system, [29]) was used to conduct the trim optimization for the vibration reduction and performance improvement of the XH-59A rotor in high-speed forward flight [27]. In addition, a validation study of the performance, loads, and vibration was conducted using CAMRAD II (comprehensive analytical method of rotorcraft aerodynamics and dynamics II, [30]) for the $\mathrm{XH}-59 \mathrm{~A}$ rotor in hover and forward flight conditions [28]. However, there is no research using the rotorcraft comprehensive analyses for the vibration reduction of the liftoffset rotor using IBC. The IBC has an advantage that the actuation frequency is not limited and is more appropriate for the lift-offset rotor than the active trailing-edge flap and active twist rotors since the lift-offset rotor uses rigid blades with high stiffness.

Therefore, this paper is aimed at reducing the vibration of the lift-offset rotor using IBC in high-speed flights. As the lift-offset rotor, the XH-59A rotor is considered and CAMRAD II is used to analyze the vibration and performance of the XH-59A rotor using IBC. When $3 /$ rev hub vibratory loads are minimized using the IBC with a single harmonic input, a decrease in the rotor effective lift-to-drag ratio is investigated. In addition, it is shown that the vibration reduction and performance improvement of the lift-offset rotor can be simultaneously obtained when $2 / \mathrm{rev}$ and $3 / \mathrm{rev}$ actuations are applied in combination for the IBC using multiple harmonic inputs. This study for the XH-59A lift-offset rotor using IBC does not correlate the analysis results of vibration reduction and performance improvement with the measured data, since there is not the test data for vibration and performance of a lift-offset rotor using IBC. Furthermore, the present work is the first attempt for the study of the lift-offset 
rotor using IBC. However, it is believed that this work will show reasonable prediction results because the present analysis model without IBC has already been validated well in the authors' previous work [28] and CAMRAD II has moderate or good prediction capability to investigate the vibration and performance of the rotor using IBC [13].

\section{Analytical Methods}

2.1. Analytical Model. The XH-59A lift-offset rotor is used as an analysis model using IBC in this work. The XH-59A helicopter using $\mathrm{ABC}^{\mathrm{TM}}$ was initially developed as a pure helicopter configuration without auxiliary propulsions in 1964 [1]. After flight tests in pure helicopter mode were conducted successfully in 1973, two auxiliary propulsions were added to the aircraft for transformation into a compound helicopter ([1], Figure 1). Table 1 summarizes the general properties of the XH-59A helicopter [1]. It is well known that the hub vibration characteristics of a lift-offset rotor are dependent of the crossover angle [26]. The crossover angle is defined as the rotor azimuth angle where the upper and lower blades of a rigid coaxial rotor crossover each other (Figure 2). When a crossover angle of $0^{\circ}$ is used for the $\mathrm{XH}-59 \mathrm{~A}$ rotor, the $3 / \mathrm{rev}$ hub axial force, normal force, and pitch moment are only transmitted to the fuselage because of interrotor cancellation $[5,26]$. In addition, the pitch inputs with higher harmonics do not alter the interrotor cancellation characteristics of a rigid coaxial rotor [26].

2.2. Analytical Tool. This work uses CAMRAD II [30], which is a comprehensive analysis code for the performance, the aerodynamic and structural loads, and the aeroelastic stability of rotorcrafts. CAMRAD II includes nonlinear finite elements, multibody dynamics, and rotorcraft aerodynamics along with various inflow or wake models. The finite elements of nonlinear elastic beam components are used for the structural dynamics modeling of isotropic or composite rotor blades. A finite beam element has a total of 15 degrees of freedom. The liftingline theory with the unsteady aerodynamics is used to calculate the aerodynamic loads acting on the rotor blade. In addition, CAMRAD II has the prescribed wake, rolled-up wake, multiple-trailer wake, and multiple-trailer wake with consolidation. The Newton-Raphson method with a Jacobian matrix is used for trim tasks in CAMRAD II analysis. The thrust, rolling moment, and pitching moment are considered as the trim targets. The trim analysis usually uses a low azimuthal resolution of $15^{\circ}$.

2.3. Modeling and Analysis Techniques. The CAMRAD II model for the XH-59A rotor using IBC in the present study is based on the model constructed in the authors' previous work [28]. Therefore, most modeling and analysis techniques of the present CAMRAD II analysis are the same as those given in reference [28]. Figure 3 shows the CAM$\mathrm{RAD}$ II model for the $\mathrm{XH}-59 \mathrm{~A}$ rotor with the crossover angle of $0^{\circ}$ in this work. A blade of the XH-59A rotor is represented using seven nonlinear finite beam elements. The pitch hinge is located at the $5 \%$ blade radius. The
TABLE 1: General properties of XH-59A lift-offset compound helicopter.

\begin{tabular}{|c|c|}
\hline Hub type & Hingeless \\
\hline Radius (ft) & 18 \\
\hline Number of rotors & 2 \\
\hline Number of blades & 3 \\
\hline Total solidity, $\sigma$ & 0.127 \\
\hline \multicolumn{2}{|l|}{ Tip speed $(\mathrm{ft} / \mathrm{sec}), V_{\text {tip }}$} \\
\hline Helicopter mode & 650 \\
\hline Compound helicopter mode & 450 \\
\hline \multicolumn{2}{|l|}{ Maximum speed (knots) } \\
\hline Helicopter mode & 160 \\
\hline Compound helicopter mode & 240 \\
\hline \multicolumn{2}{|l|}{ Horizontal tail } \\
\hline Area $\left(\mathrm{ft}^{2}\right)$ & 60 \\
\hline Span $(\mathrm{ft})$ & 15.50 \\
\hline Tail length (ft) & 20.30 \\
\hline \multicolumn{2}{|l|}{ Vertical tail } \\
\hline Area $\left(\mathrm{ft}^{2}\right)$ & 30 \\
\hline Span $(\mathrm{ft})$ & 12 \\
\hline Tail length (ft) & 20.30 \\
\hline \multicolumn{2}{|l|}{ Fuselage } \\
\hline Length (ft) & 40.5 \\
\hline Width (ft) & 6.08 \\
\hline Height (ft) & 6.08 \\
\hline Rotor separation (ft) & 2.5 \\
\hline \multicolumn{2}{|l|}{ Power plants } \\
\hline Lift & PT6T-3 turboshaft engine \\
\hline Thrust & J60-P-3A turbojet engine \\
\hline
\end{tabular}

rotor control system including the pitch link, swashplates, and pitch horn is also modeled. It is assumed that the stiffness of the pitch link with the IBC actuator is the same as that of the original XH-59A rotor model used in the previous work [28]. In this work, the pitch motion by the IBC inputs applied to both the upper and lower rotors is represented using equations (1) and (2).

For a single harmonic input,

$$
\theta_{\mathrm{IBC}}=A \cos (N \psi-\phi) .
$$

For multiple harmonic inputs,

$$
\theta_{\mathrm{IBC}}=\sum_{N=2} A_{N} \cos \left(N \psi-\phi_{N}\right)
$$

where $\theta_{\mathrm{IBC}}$ is the IBC equivalent blade pitch, $\psi$ is the blade azimuth angle, and $N, A$, and $\phi$ are the actuation frequency, amplitude, and control phase angle, respectively, of the IBC inputs.

Since the actual airfoil data for the $\mathrm{XH}-59 \mathrm{~A}$ rotor are not available, the airfoils similar to the actual airfoil characteristics of the XH-59A rotor are used as given in Figure 4. 


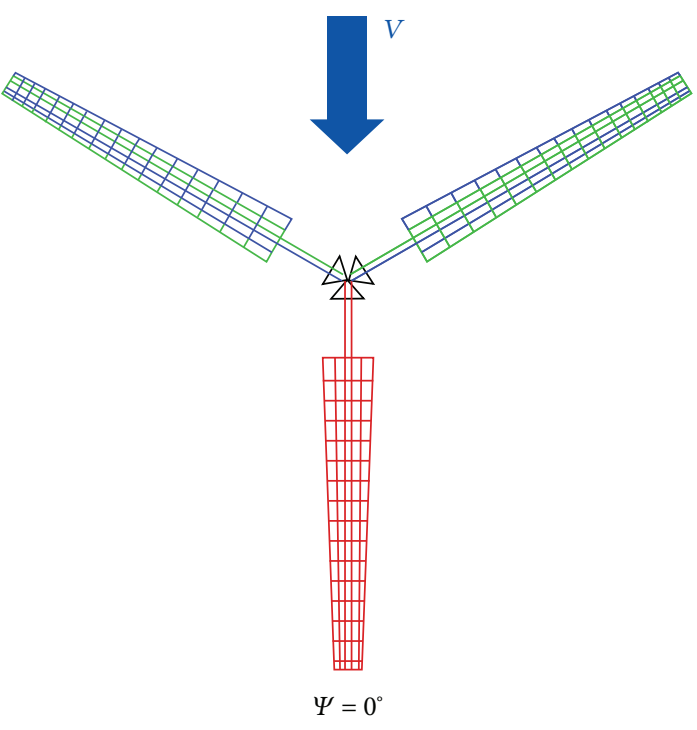

(a) Crossover angle $=0^{\circ}$

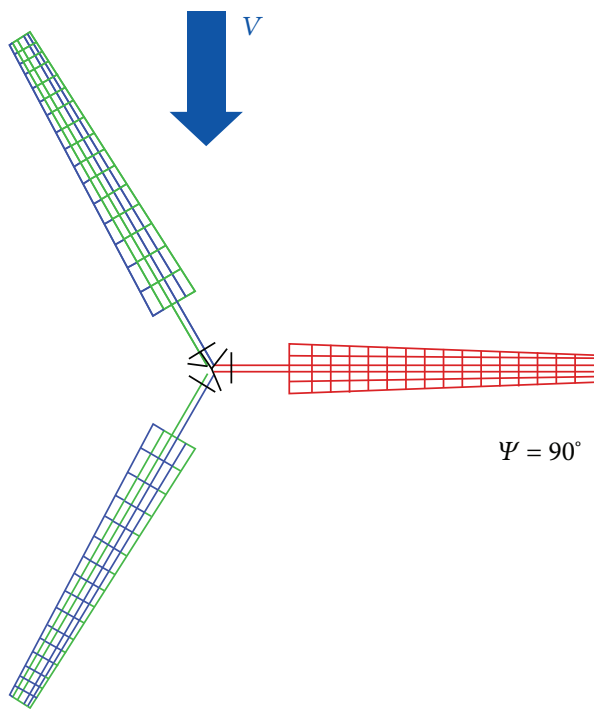

(b) Crossover angle $=90^{\circ}$

Figure 2: Definition of the crossover angle.

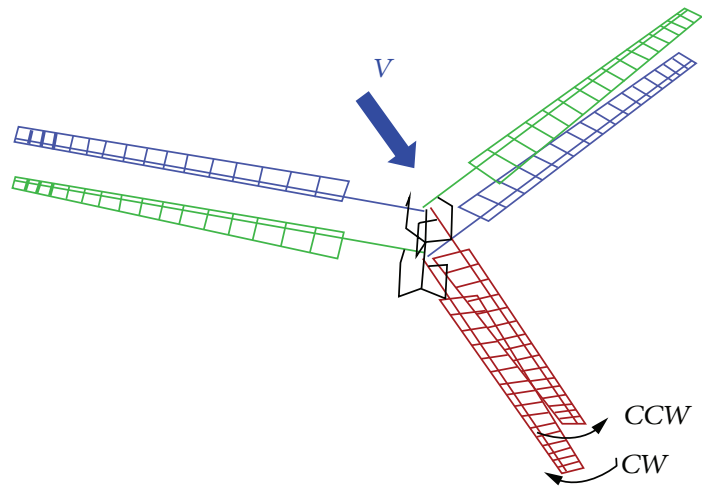

FIGURE 3: CAMRAD II model for the XH-59A rotor.

However, the drag increment is used appropriately in order to correct the aerodynamic characteristics of the airfoils used in the present analyses. Further detailed explanation for the adjustment of drag coefficients in the C81 airfoil tables is given in reference [28]. The aerodynamic loads on each blade are calculated using 16 aerodynamic panels. Unlike the authors' previous work [28], which used a general free wake model, the prescribed wake model is used in the present analyses to avoid the convergence trouble due to the application of the IBC inputs.

The trim analyses are conducted using the six primary rotor controls of the upper and lower rotors. The pitch angle of the XH-59A compound helicopter is fixed at $0^{\circ}$ since it provides the best performance for the lift-offset rotor [1]. The trim targets in the validation examples in Section 3.1 are set as the vertical force equivalent to the aircraft weight, the torque offset of the upper and lower rotors, and the hub pitching and rolling moments of the upper and lower rotors. In particular, the hub rolling moment $\left(M_{\text {roll }}\right)$ can be prescribed using the assumed lift-offset (LOS) value given in the following equation:

$$
\text { LOS }=\frac{M_{\text {roll }}}{T R},
$$

where $T$ is the thrust of each rotor.

For the propulsive trim, which will be used in Sections 3.2 and 3.3, the drag force of each rotor is considered as the trim target instead of the pitching moment of each rotor. In the present analyses, the drag forces obtained from the validation examples in Section 3.1 are used as the target values of drag forces for the propulsive trim.

The 3/rev hub vibratory loads of the XH-59A rotor are calculated using the following:

$$
\begin{gathered}
F_{3 P}=\sqrt{\left[F_{3 P_{C}}^{\text {upper }}+F_{3 P_{C}}^{\text {lower }}\right]^{2}+\left[F_{3 P_{S}}^{\text {upper }}+F_{3 P_{S}}^{\text {lower }}\right]^{2}}, \\
M_{3 P}=\sqrt{\left[M_{3 P_{C}}^{\text {upper }}+M_{3 P_{C}}^{\text {lower }}\right]^{2}+\left[M_{3 P_{S}}^{\text {upper }}+M_{3 P_{S}}^{\text {lower }}\right]^{2}},
\end{gathered}
$$

where $F$ and $M$ are the hub forces and moments, respectively. In addition, the superscripts upper and lower mean the upper and lower rotors, respectively, and the subscripts $C$ and $S$ represent the cosine and sine components, respectively, of the hub loads.

The vibration index (VI) [31] to evaluate the vibration level of the XH-59A rotor is defined as

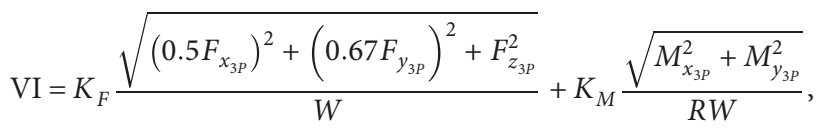

where $W$ is the aircraft weight. In addition, $K_{F}$ and $K_{M}$ are assumed as unity in this work. It should be noted that the interrotor cancellation of a lift-offset rotor [26] is considered 


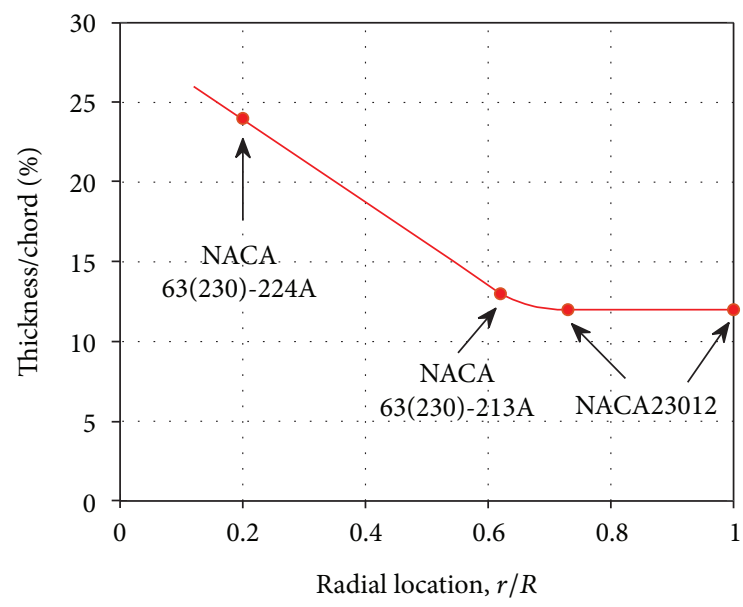

(a) Actual airfoils

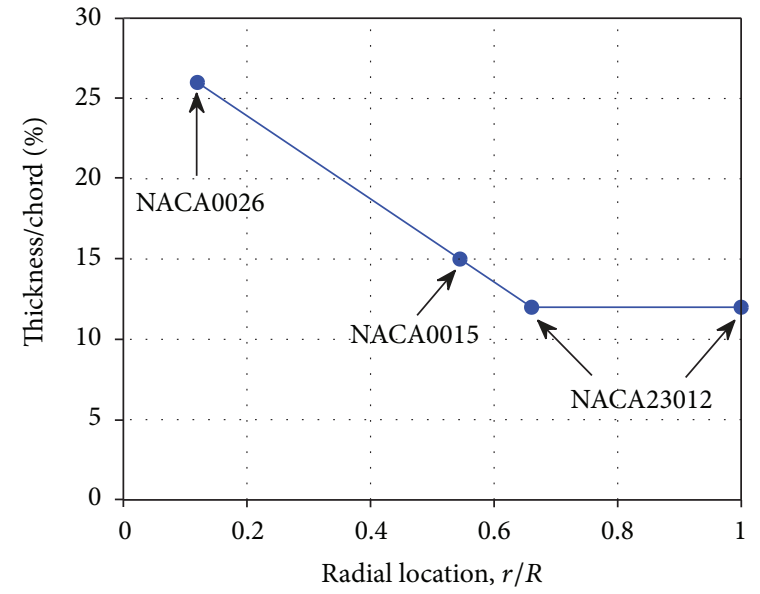

(b) Present airfoils

FIGURE 4: Blade thickness and airfoil distribution.

when the vibration index is calculated. Furthermore, the $6 /$ rev hub load components are not considered in equation (5) since the $3 /$ rev hub vibratory loads are the most dominant for the XH-59A rotor [26] and predictions of the 6/rev hub vibratory loads are not validated in this paper.

The rotor power $(P)$ of each of the upper and lower rotors for performance calculation of the lift-offset rotor is defined as

$$
P=P_{\mathrm{i}}+P_{\mathrm{o}}+P_{\mathrm{p}}
$$

where $P_{\mathrm{i}}, P_{\mathrm{o}}$, and $P_{\mathrm{p}}$ are the induced power, profile power, and parasite power, respectively.

The rotor effective lift-to-drag ratio $\left(L / D_{\mathrm{e}}\right)$ to evaluate the rotor performance is defined as

$$
\frac{L}{D_{\mathrm{e}}}=\frac{L}{\left(P_{\text {coaxial }} / V+X\right)},
$$

where $P_{\text {coaxial }}$ is the power of the lift-offset rotor which is the sum of each power of the upper and lower rotors. In addition, $V$ and $X$ are the flight speed and drag force, respectively, of the lift-offset rotor.

\section{Results and Discussions}

3.1. Validation. The modeling and analysis techniques of CAMRAD II using the prescribed wake model are validated for the XH-59A rotor without IBC in this section. For the analyses, the $\mathrm{XH}-59 \mathrm{~A}$ rotor in compound helicopter mode with auxiliary propulsions (gross weight of $13000 \mathrm{lb}$ ) is considered and the lift-offset of 0.25 is used. Figure 5 shows the correlation of the rotor effective lift-to-drag ratio in forward flight between the present prediction and flight test data [32]. The flight test data in Figure 5 are for a gross weight ranging from 11000 to $13000 \mathrm{lb}$. As seen in the figure, the present prediction compares well with the flight test data since the CAMRAD II analysis result is within the upper and lower bounds of the flight test data and the variation of

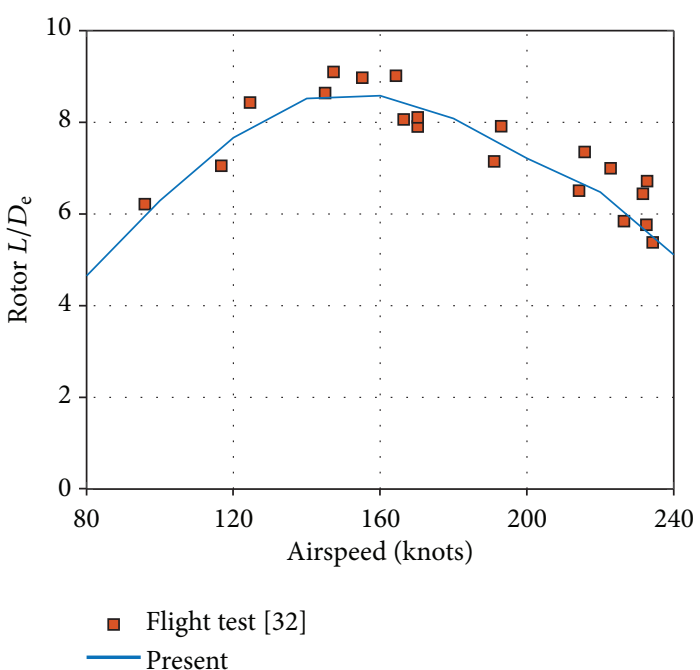

FIGURE 5: Validation of the rotor effective lift-to-drag ratio.

the predicted result is similar to that of the test data. Figure 6 compares the predicted 3/rev hub pitch moment with the flight test data [1] for the XH-59A rotor with a crossover angle of $0^{\circ}$. Although correlations between the present analysis and test data are given at only two flight speed conditions in the figure, the present CAMRAD II analysis predicts well the $3 /$ rev hub pitch moment. As given in Figures 5 and 6 , it is considered that the present modeling and analysis techniques to predict the rotor performance and vibration are well established.

3.2. IBC Using a Single Harmonic Input. In this section, the $3 /$ rev hub vibratory loads and rotor performance are investigated when the IBC with a single harmonic input (equation (1)) is used for the XH-59A rotor at a flight speed of 200 knots. For the IBC with a single harmonic input, three actuation frequencies $(N)$ of 2,3 , and $4 / \mathrm{rev}$ and two IBC amplitudes $(A)$ of 1 and $2^{\circ}$ are used. The control phase angle $(\phi)$ 


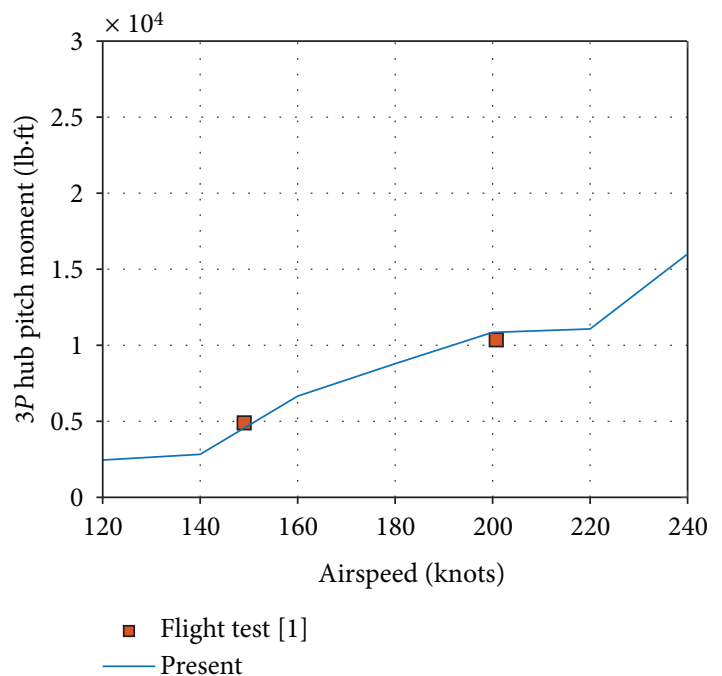

FIGURE 6: Validation of 3/rev hub pitch moment.

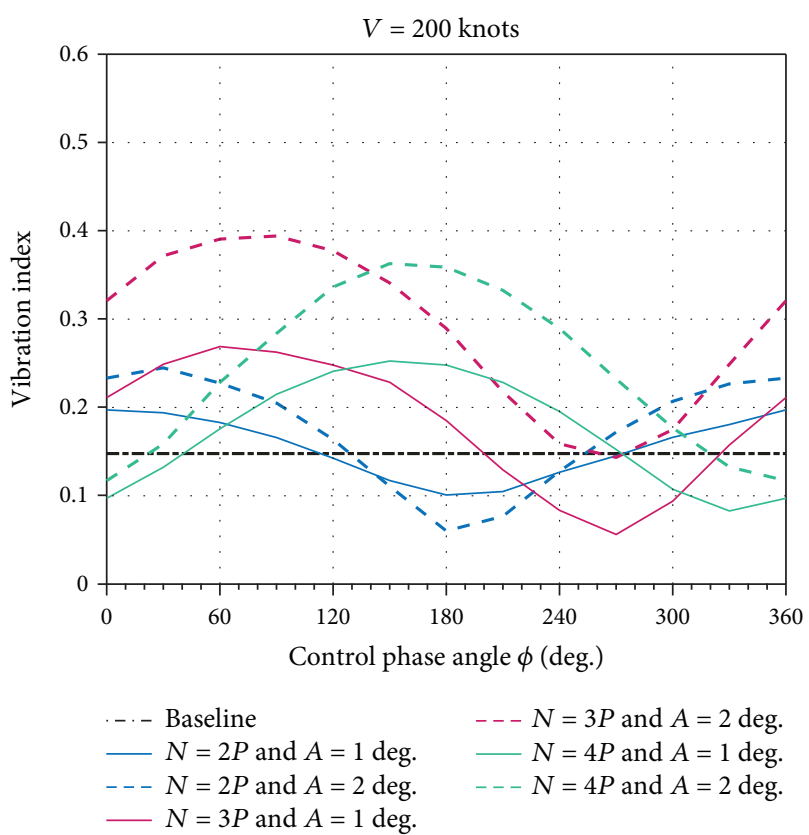

FIGURE 7: Vibration index in terms of control phase angle for IBC using a single harmonic input.

from 0 to $360^{\circ}$ is considered with an increment of $30^{\circ}$. The propulsive trim is used for the analyses with and without the IBC, as previously described.

3.2.1. Rotor Vibration. Figure 7 shows the change in the vibration index (equation (5)) of the XH-59A rotor in terms of the control phase angle. The baseline indicates the result when the IBC is not applied. As seen in the figure, the vibration index of the XH-59A rotor changes (increases or decreases) significantly when the IBC with a single harmonic input is used. The vibration index is reduced by about $59.3 \%$ from the baseline value when the actuation frequency of

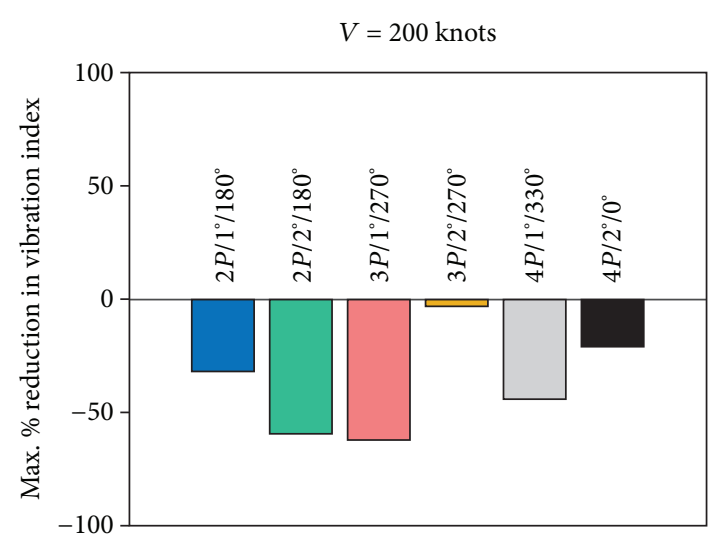

FIGURE 8: Maximum reduction in vibration index for various IBC conditions using a single harmonic input.

$2 / \mathrm{rev}, \mathrm{IBC}$ amplitude of $2^{\circ}$, and control phase of $180^{\circ}(2 P$ $\left.12^{\circ} / 180^{\circ}\right)$ are used for IBC. In addition, when the IBC with $3 P / 1^{\circ} / 270^{\circ}$ is used, the vibration index is minimized with a reduction of about $62 \%$ as compared to the baseline value. The IBC using $4 P / 1^{\circ} / 330^{\circ}$ also moderately reduces the vibration index by approximately $44 \%$. However, the vibration index is reduced by about $3 \%$ only when the IBC with $3 P$ $12^{\circ} / 270^{\circ}$ is applied. The maximum reduction in the vibration index is summarized in Figure 8 for various IBC input conditions. As shown in Figures 7 and 8, the IBC inputs using $2 P$ $12^{\circ} / 180^{\circ}$ and $3 P / 1^{\circ} / 270^{\circ}$ both show excellent vibration reductions of the XH-59A rotor by about 59.3 and $62 \%$, respectively.

Changes in the $3 / \mathrm{rev}$ hub load components in terms of the control phase angle are investigated in Figure 9. As given in the figures, the variation trends for two different IBC amplitudes of 1 and $2^{\circ}$ are similar to each other with the given actuation frequency. The 3/rev hub axial force in Figure 9(a) is minimized by approximately $73.1 \%$ from the baseline value when the IBC using $3 P / 2^{\circ} / 120^{\circ}$ is applied. Figure 9 (b) shows that the $3 / \mathrm{rev}$ hub normal force is minimized by about $83.8 \%$ when the IBC input of $3 P / 1^{\circ} / 270^{\circ}$ is used. The IBC using $3 P$ $/ 1^{\circ} / 240^{\circ}$ in Figure 9 (c) minimizes the $3 /$ rev hub pitch moment by about $65.4 \%$ to the baseline value. As shown in Figure 9, the IBC input conditions are different to minimize the $3 /$ rev hub axial force, normal force, and pitch moment. However, all of the $3 / \mathrm{rev}$ hub load components are minimized by the IBC using the $3 /$ rev actuation frequency.

Figure 10 summarizes the maximum reductions in the $3 /$ rev hub axial force, normal force, and pitch moment for the given actuation frequency and IBC amplitude and shows the corresponding control phase angles. Particularly, the IBC using $4 P / 2^{\circ} / 330^{\circ}$ minimizes the $3 / \mathrm{rev}$ hub pitch moment but its reduced value is higher than the baseline value by $50 \%$. As shown in the figures, there is no control phase angle, which simultaneously minimizes the $3 / \mathrm{rev}$ hub axial force, normal force, and pitch moment for the given actuation frequency and IBC amplitude. Furthermore, when two IBC amplitudes of 1 and $2^{\circ}$ are considered with the given actuation frequency, the control phase angle is the same to minimize the $3 / \mathrm{rev}$ hub load component. 


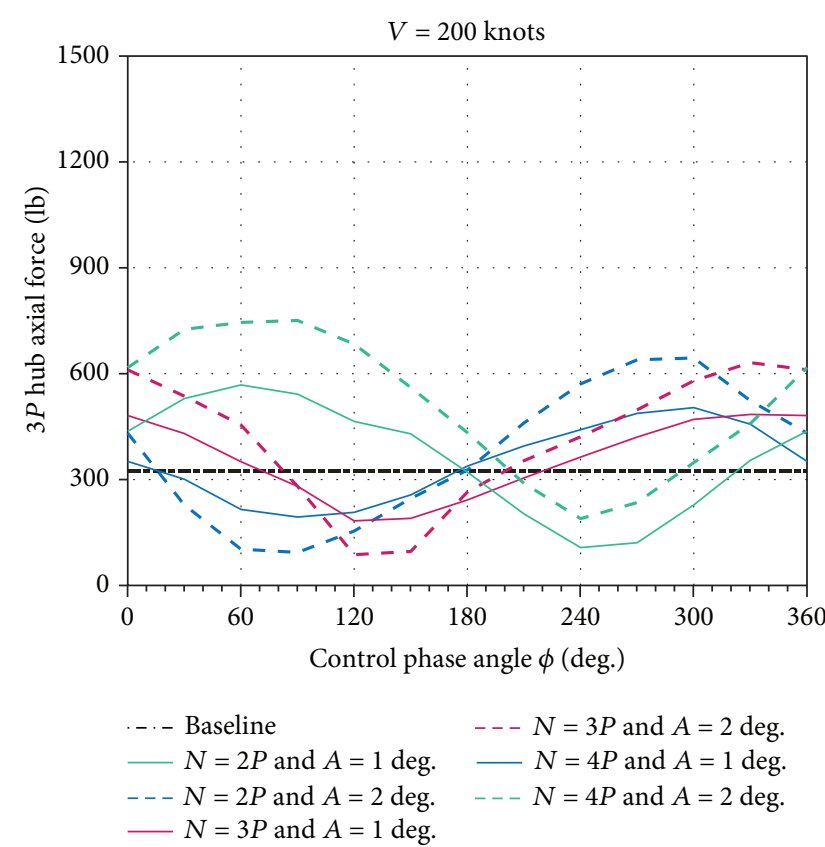

(a) Axial force

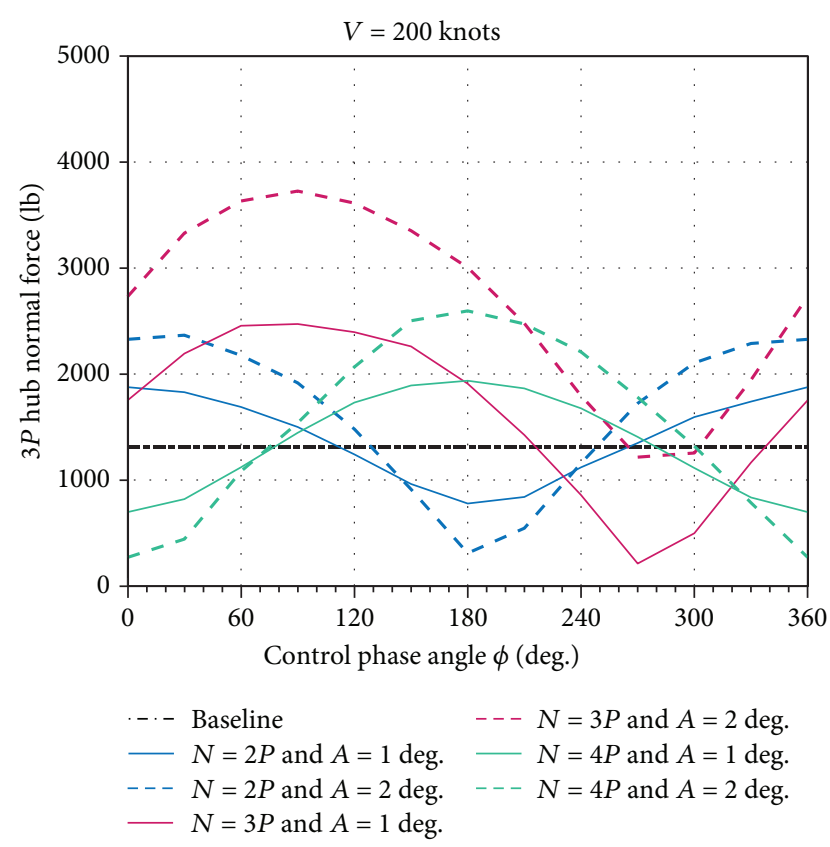

(b) Normal force

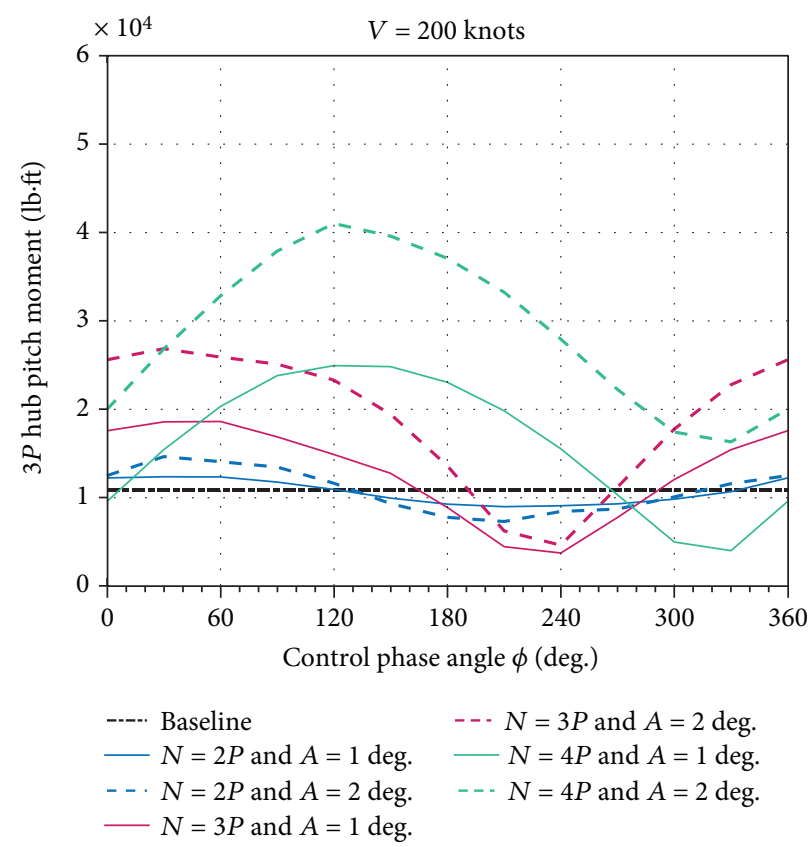

(c) Pitch moment

FIGURE 9: 3/rev hub vibratory load components in terms of control phase angle of IBC using a single harmonic input.

As shown in Figures 7-10, two IBC input conditions, $2 P$ $12^{\circ} / 180^{\circ}$ and $3 P / 1^{\circ} / 270^{\circ}$, are appropriate to reduce significantly the vibration index of the XH-59A rotor at 200 knots. In addition, the control phase angle to minimize the vibration index is the same as that to minimize the $3 / \mathrm{rev}$ hub normal force when the actuation frequency and IBC amplitude are given. For these two IBC input conditions, the $3 / \mathrm{rev}$ hub normal force is minimized the most as compared to the reductions in the other $3 / \mathrm{rev}$ hub load components. Therefore, the control phase angle to minimize the vibration index is also the same as the control phase angle, which provides the greatest maximum reduction in the $3 / \mathrm{rev}$ hub load components. However, it is known that the $3 / \mathrm{rev}$ pitch moment of the $\mathrm{XH}-59 \mathrm{~A}$ rotor is the most dominant to excite the airframe in high-speed flights when a crossover angle of $0^{\circ}$ is used $[1,26]$.

3.2.2. Rotor Performance. The variations of the rotor effective lift-to-drag ratio are given in Figure 11 when the IBC with a single harmonic input is used for the XH-59A rotor at 200 


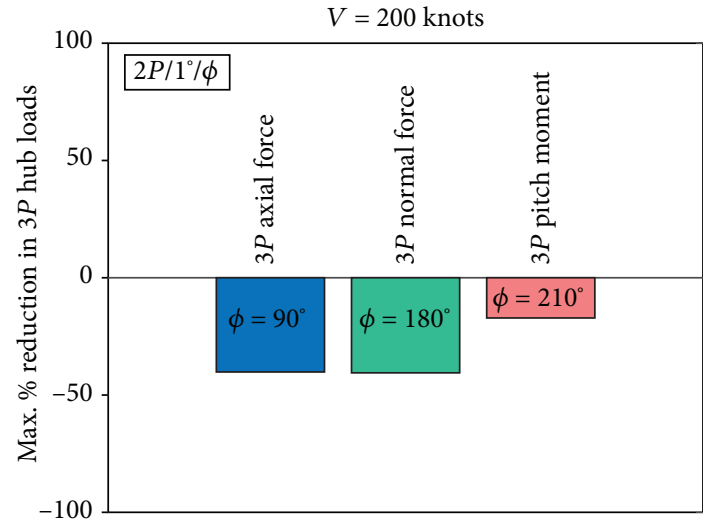

(a) $2 P / 1^{\circ} / \varphi$

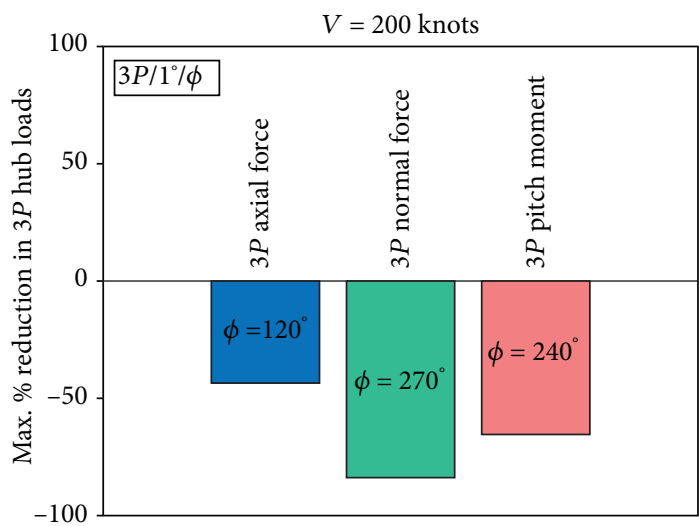

(c) $3 P / 1^{\circ} / \varphi$

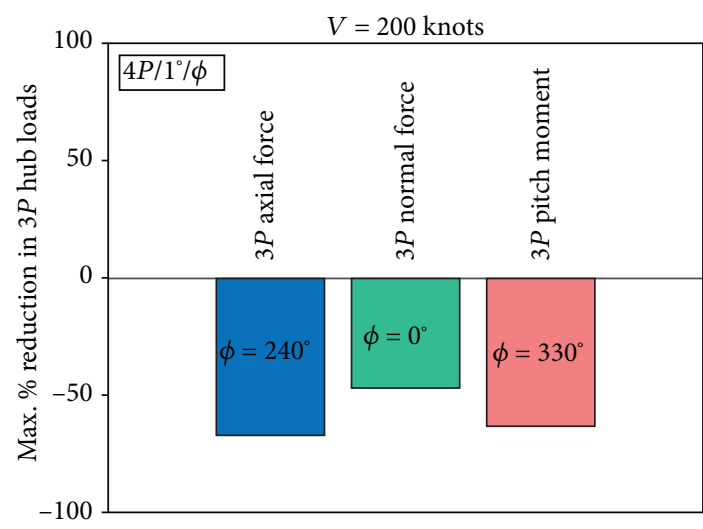

(e) $4 P / 1^{\circ} / \varphi$

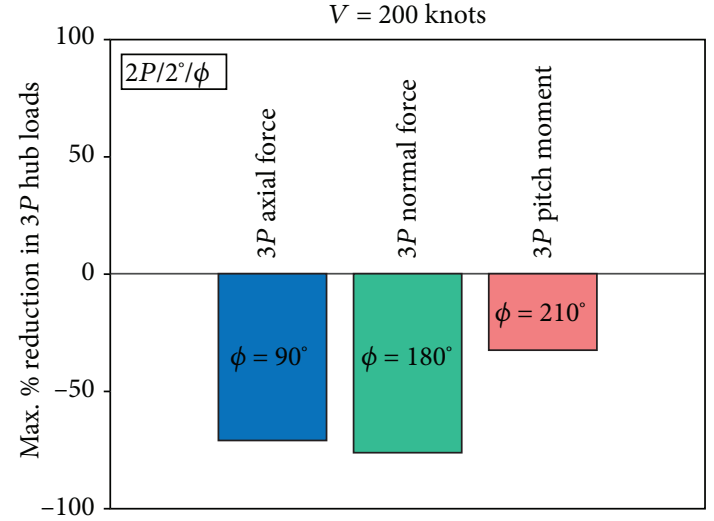

(b) $2 P / 2^{\circ} / \varphi$

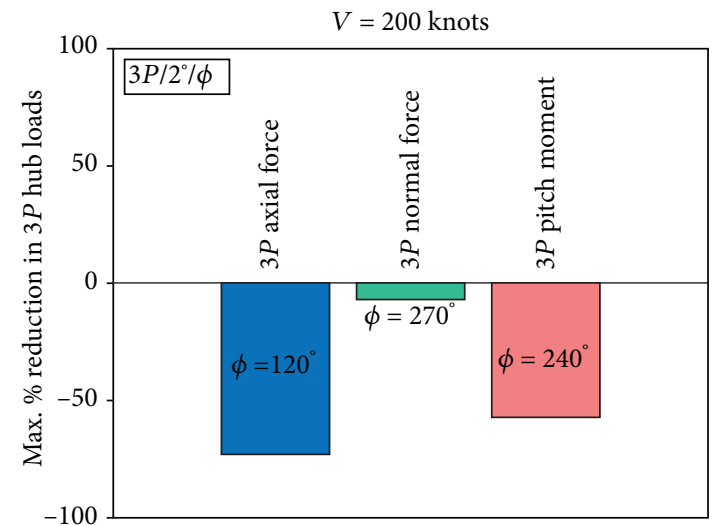

(d) $3 P / 2^{\circ} / \varphi$

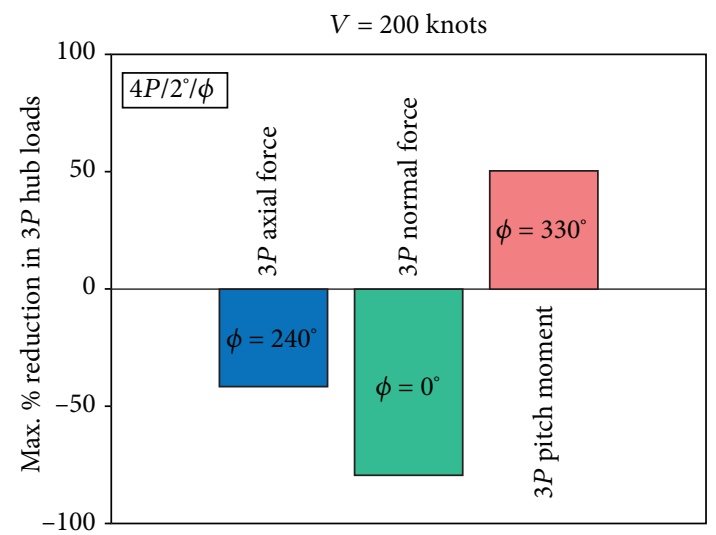

(f) $4 P / 2^{\circ} / \varphi$

FIGURE 10: IBC input conditions using a single harmonic input for maximum reduction in 3/rev hub vibratory load components.

knots. As shown in the figure, the rotor performance increases or decreases by the IBC application. When Figures 7 and 11 are compared, it is easily known that the IBC input to minimize the vibration of the $\mathrm{XH}-59 \mathrm{~A}$ rotor reduces the rotor performance. For an example, the IBC using $3 P / 1^{\circ} / 270^{\circ}$ which minimizes the vibration index by about $62 \%$ reduces the rotor effective lift-to-drag ratio by about $3.43 \%$ as compared to the baseline performance. In other words, it is difficult to obtain the vibration reduction and performance improvement of a lift-offset rotor simultaneously when using the IBC with a single harmonic input. Figure 12 summarizes the maximum improvement of the rotor effective lift-to-drag ratio for various IBC input conditions. The IBC with $2 P / 2^{\circ} / 0^{\circ}$ maximizes the rotor performance of the $\mathrm{XH}-59 \mathrm{~A}$ rotor by $3.18 \%$ to the baseline value. However, the IBC using the $4 / \mathrm{rev}$ actuation does not increase the rotor effective lift-to-drag ratio but decreases the rotor performance, as seen in Figures 11 and 12, although the IBC using 4/rev actuation reduces the vibration index discussed previously in Figures 7 and 8. 


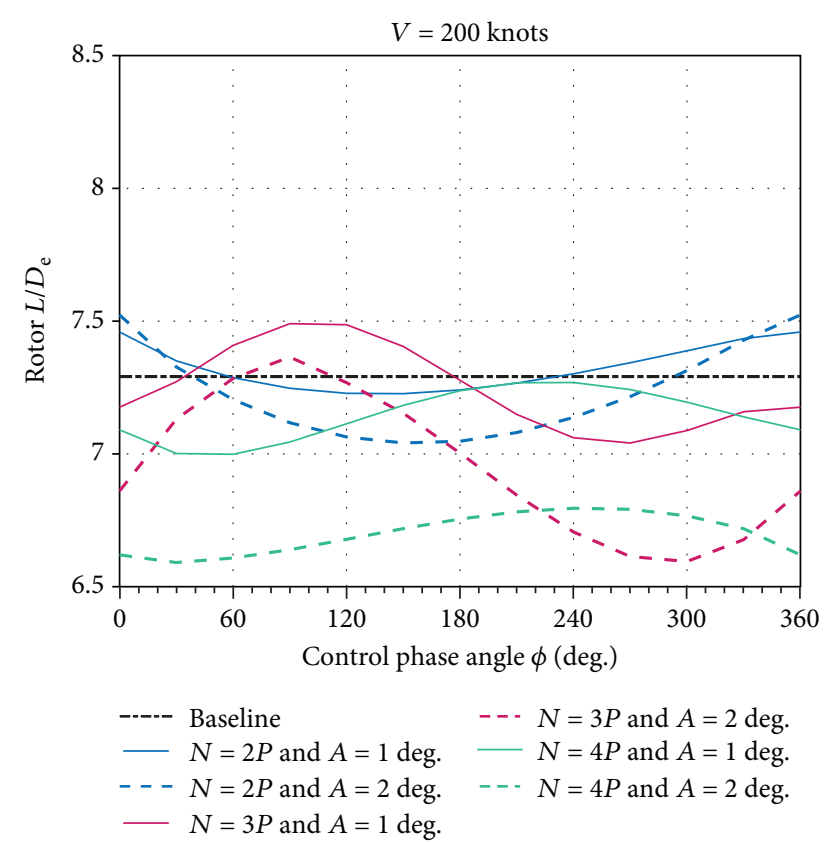

FIGURE 11: Rotor effective lift-to-drag ratio in terms of control phase angle of IBC using a single harmonic input.

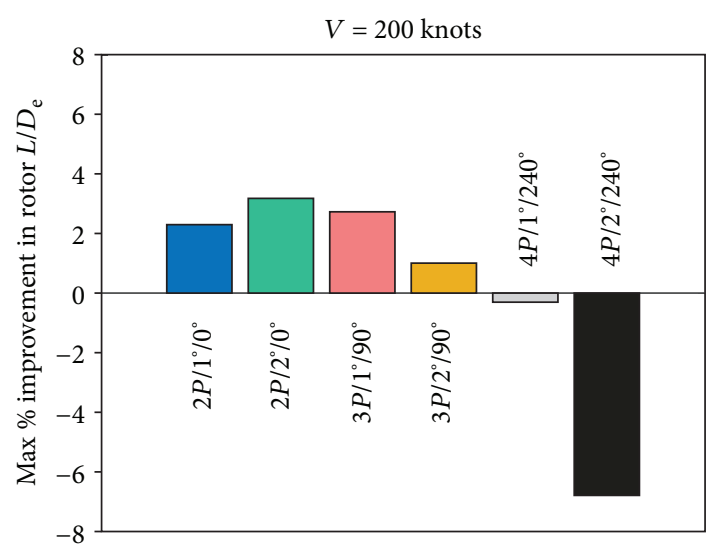

Figure 12: Maximum improvement in rotor effective lift-to-drag ratio for various IBC conditions using a single harmonic input.

3.3. IBC Using Multiple Harmonic Inputs. As shown in the previous section, the IBC using a single harmonic input reduces significantly the vibration index of the $\mathrm{XH}-59 \mathrm{~A}$ rotor at a flight speed of 200 knots; however, the rotor effective liftto-drag ratio is reduced when the IBC condition to minimize the rotor vibration is used. Therefore, a new input scenario of IBC is required to reduce significantly the hub vibratory loads while maintaining or increasing the rotor performance of a lift-offset rotor in high-speed flights. In this section, the IBC using multiple harmonic inputs is proposed to reduce the vibration index and increase the rotor effective lift-todrag ratio (or at least maintain the baseline value) of the $\mathrm{XH}-59 \mathrm{~A}$ rotor at 200 knots, simultaneously. The different actuation frequencies $(N)$, IBC amplitudes $\left(A_{N}\right)$, and control

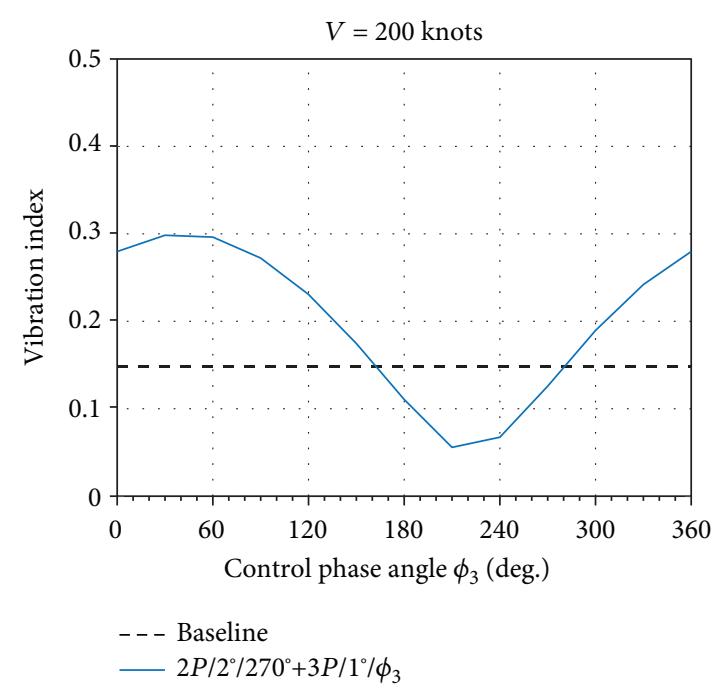

FIgURE 13: Vibration index in terms of control phase angle $\left(\phi_{3}\right)$ of IBC using multiple harmonic inputs.

phase angles $\left(\phi_{N}\right)$ are combined using equation (2) for the IBC with multiple harmonic inputs.

Two actuation frequencies of $2 / \mathrm{rev}$ and $3 / \mathrm{rev}$, two IBC amplitudes of 1 and $2^{\circ}$, and control phase angles from 0 to $360^{\circ}$ with an increment of $30^{\circ}$ are combined for the IBC with multiple harmonic inputs. As previously discussed in Section 3.2 , since the IBC using a $4 / \mathrm{rev}$ actuation does not increase the rotor performance, the $4 / \mathrm{rev}$ actuation is not considered for multiple harmonic inputs of IBC. Actually, it is an optimization problem to find the conditions of multiple harmonic inputs for IBC, which simultaneously minimizes the vibration and maximizes the performance of the lift-offset rotor in high-speed flights. However, the goal of this study is not to search for the optimal input condition for simultaneous vibration minimization and performance maximization of the $\mathrm{XH}-59 \mathrm{~A}$ rotor. Instead, this paper shows an example using the IBC with multiple harmonic inputs, which reduces the vibration index significantly and increases slightly the rotor effective lift-to-drag ratio of the XH-59A, simultaneously. Two input conditions of $2 P / 2^{\circ} / 270^{\circ}$ and $3 P / 1^{\circ} / \phi_{3}$ are combined for the IBC using multiple harmonic inputs.

3.3.1. Rotor Vibration. Figure 13 shows the variation of the vibration index of the $\mathrm{XH}-59 \mathrm{~A}$ rotor at $200 \mathrm{knots}$, using the IBC with the multiple harmonic inputs; $\theta_{\mathrm{IBC}}=2 \cos (2 \psi-$ $\left.270^{\circ}\right)+1 \cos \left(3 \psi-\phi_{3}\right)$. As shown in the figure, the vibration index increases or decreases as the control phase angle for the $3 / \mathrm{rev}$ actuation $\left(\phi_{3}\right)$ varies. The vibration index is minimized by about $62 \%$ from the baseline value when a control phase angle $\left(\phi_{3}\right)$ of $210^{\circ}$ is used for the IBC with multiple harmonic inputs. The capability of this vibration reduction is exactly equivalent to that using the IBC with the single harmonic input of $3 P / 1^{\circ} / 270^{\circ}$ given in Figures 7 and 8 .

Figure 14 exhibits the variations of the $3 / \mathrm{rev}$ hub axial force, normal force, and pitch moment in terms of the control phase angle $\left(\phi_{3}\right)$ for the IBC using multiple harmonic inputs. Although the vibration index is reduced seriously from the baseline result given in Figure 13, the 3/rev hub axial 


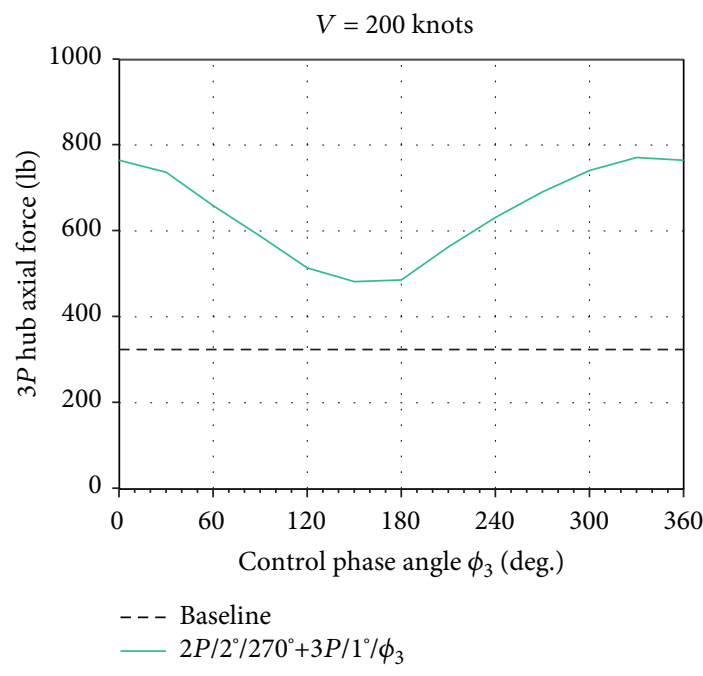

(a) Axial force

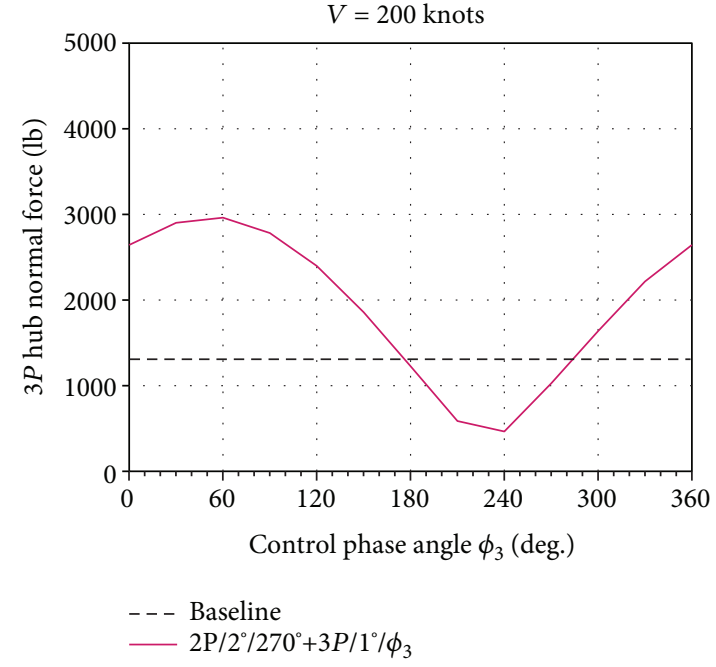

(b) Normal force

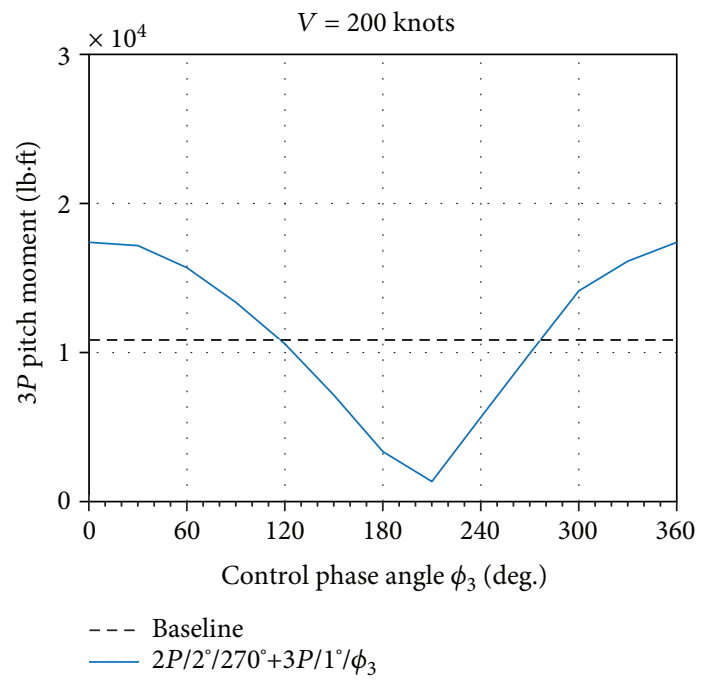

(c) Pitch moment

FIGURE 14: 3/rev hub vibratory load components in terms of control phase angle $\left(\phi_{3}\right)$ of IBC using multiple harmonic inputs.

force in Figure 14(a) is not reduced than the corresponding baseline value since its minimized value is higher than the baseline value by about $48.8 \%$. The $3 /$ rev hub normal force in Figure 14(b) is minimized by approximately $64.5 \%$ to the baseline value when the IBC using the multiple harmonic inputs with a $\phi_{3}$ of $240^{\circ}$ is used. The variation of the $3 / \mathrm{rev}$ hub pitch moment is given in Figure 14(c). The multiple harmonic inputs using a $\phi_{3}$ of $210^{\circ}$ minimize the $3 / \mathrm{rev}$ hub pitch moment with a reduction of about $87.6 \%$ from the baseline value. Figure 15 summarizes the maximum reduction in $3 /$ rev hub load components and the corresponding IBC input conditions using multiple harmonic inputs. When the IBC using multiple harmonic inputs is applied, the $3 / \mathrm{rev}$ hub pitch moment is minimized the most as compared to the other 3/rev hub load components. As shown in Figures 14 and 15 , the control phase angle for the $3 / \mathrm{rev}$ actuation $\left(\phi_{3}\right)$ to minimize the vibration index is the same as the control

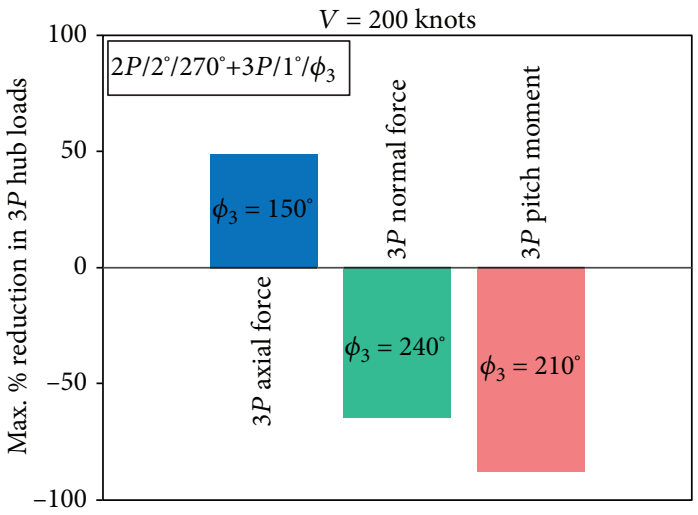

FIGURE 15: IBC input conditions using multiple harmonic inputs for maximum reduction in $3 / \mathrm{rev}$ hub vibratory load components. 


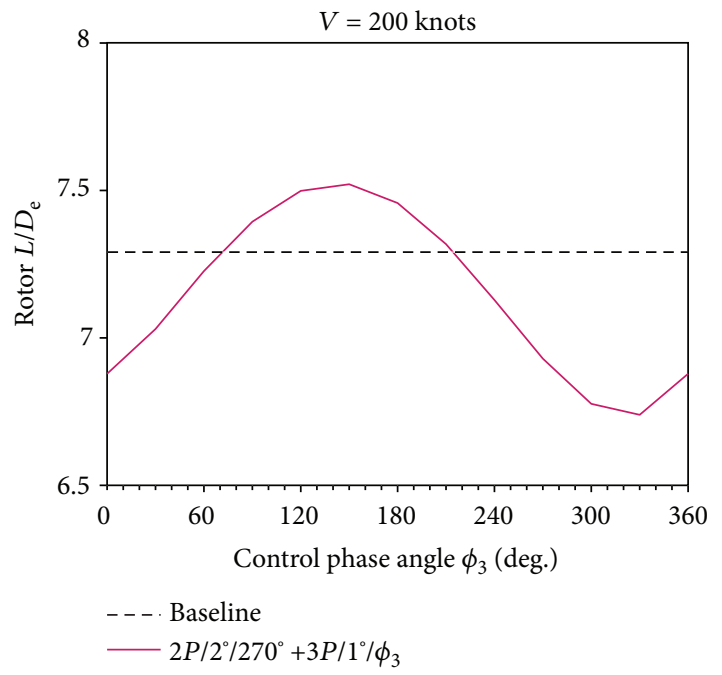

FIGURE 16: Rotor effective lift-to-drag ratio in terms of control phase angle $\left(\phi_{3}\right)$ of IBC using multiple harmonic inputs.

TABLE 2: Changes in vibration and rotor performance using IBC with multiple harmonic inputs.

\begin{tabular}{lcc}
\hline Control phase angle $\left(\phi_{3}\right)$ & \multicolumn{2}{c}{ Percent change } \\
& Vibration index & $\begin{array}{c}\text { Rotor effective } \\
\text { lift-to-drag ratio }\end{array}$ \\
\hline $190^{\circ}$ & -37.53 & 1.64 \\
$195^{\circ}$ & -43.71 & 1.33 \\
$200^{\circ}$ & -50.00 & 1.01 \\
\hline
\end{tabular}

phase angle $\left(\phi_{3}\right)$, which gives the greatest maximum reduction in the $3 / \mathrm{rev}$ hub load components.

3.3.2. Rotor Performance. Figure 16 shows the variation of the rotor effective lift-to-drag ratio in terms of the control phase angle $\left(\phi_{3}\right)$ for the IBC using multiple harmonic inputs; $\theta_{\mathrm{IBC}}=2 \cos \left(2 \psi-270^{\circ}\right)+1 \cos \left(3 \psi-\phi_{3}\right)$. When the control phase angle $\left(\phi_{3}\right)$ is $150^{\circ}$, the rotor performance is maximized by $3.16 \%$ as compared to the baseline value. The rotor effective lift-to-drag ratio increases by $0.37 \%$ when a control phase angle $\left(\phi_{3}\right)$ of $210^{\circ}$, which minimizes the vibration index as given in Figure 13, is used. Therefore, the IBC using multiple harmonic inputs, $\theta_{\mathrm{IBC}}=2 \cos$ $\left(2 \psi-270^{\circ}\right)+1 \cos \left(3 \psi-210^{\circ}\right)$, significantly reduces the rotor vibration while it slightly increases the rotor performance for the XH-59A lift-offset rotor at 200 knots.

When two present prediction result sets using control phase angles $\left(\phi_{3}\right)$ of 180 and $210^{\circ}$ are interpolated, the vibration reduction and rotor performance improvement of the $\mathrm{XH}-59 \mathrm{~A}$ rotor are summarized as shown in Table 2 . As given in the table, when a control phase angle $\left(\phi_{3}\right)$ of $200^{\circ}$ is used for the present multiple harmonic inputs of IBC, the rotor vibration is reduced by about $50 \%$ from the baseline value and the rotor performance is improved by approximately $1.01 \%$ as compared to the baseline result, simultaneously. It is not easy to obtain this outperformance in the simultaneous vibration reduction and performance improvement of the
$\mathrm{XH}-59 \mathrm{~A}$ rotor when the IBC using a single harmonic input is used.

\section{Conclusions}

In this work, the vibration and performance of the XH-59A lift-offset rotor using IBC were investigated by the rotorcraft comprehensive analysis code, CAMRAD II. At a flight speed of 200 knots, the vibration index was minimized by about $62 \%$ from the baseline value but the rotor effective lift-todrag ratio was reduced by about $3.43 \%$ to the baseline result when the actuation frequency of $3 / \mathrm{rev}$, amplitude of $1^{\circ}$, and control phase of $270^{\circ}\left(3 \mathrm{P} / 1^{\circ} / 270^{\circ}\right)$ were used for the IBC with a single harmonic input. However, when the IBC with multiple harmonic inputs, $\theta_{\mathrm{IBC}}=2 \cos \left(2 \psi-270^{\circ}\right)+1 \cos (3 \psi-$ $210^{\circ}$ ), was used for the XH-59A rotor at 200 knots, the rotor vibration was reduced by about $62 \%$ and the rotor performance was improved by about $0.37 \%$ from the baseline value. Using the obtained prediction results, the vibration index was reduced by approximately $50 \%$ while the rotor effective liftto-drag ratio increased by about $1.01 \%$ when the IBC using $\theta_{\mathrm{IBC}}=2 \cos \left(2 \psi-270^{\circ}\right)+1 \cos \left(3 \psi-200^{\circ}\right)$ was applied to the $\mathrm{XH}-59 \mathrm{~A}$ lift-offset rotor at 200 knots. In the future, a physical understanding of the analysis results given in this paper will be investigated thoroughly along with other prediction results including the trimmed pitch control angles, rotor airloads, blade structural loads, blade elastic deformations, and blade tip clearance. In addition, an optimization study of the input scenario for the IBC using multiple harmonic inputs, which minimizes the vibration reduction and maximizes the rotor performance of the lift-offset rotor simultaneously, will be conducted.

\section{Nomenclature}

A: $\quad$ Actuation amplitude of IBC (deg.)

$D: \quad$ Drag force (lb)

$F_{3 P}: \quad 3 /$ rev hub force (lb)

L: $\quad$ Lift force (lb)

$L / D_{\mathrm{e}}: \quad$ Rotor effective lift-to-drag ratio

$M_{3 P}: \quad 3 /$ rev hub moment (lb·ft)

$M_{\text {roll }}$ : Hub rolling moment $(\mathrm{lb} \cdot \mathrm{ft})$

$N: \quad$ Actuation frequency of IBC (/rev)

$N_{\mathrm{b}}$ : Number of blades of each rotor

P: $\quad$ Per revolution (/rev)

$P$ : $\quad$ Rotor power (hp)

$P_{\text {coaxial }}:$ Coaxial rotor power (hp)

$P_{\mathrm{i}}: \quad$ Induced power $(\mathrm{hp})$

$P_{\mathrm{o}}$ : $\quad$ Profile power (hp)

$P_{\mathrm{p}}: \quad$ Parasite power (hp)

$r: \quad$ Radial position of the rotor $(\mathrm{ft})$

$R: \quad$ Radius of the rotor $(\mathrm{ft})$

$T: \quad$ Thrust (lb)

$V: \quad$ Flight speed ( $\mathrm{ft} / \mathrm{sec})$

$V_{\text {tip }}: \quad$ Hover tip velocity of the rotor $(\mathrm{ft} / \mathrm{sec})$

$W: \quad$ Weight of the aircraft (lb)

$X: \quad$ Wind axis drag force of the rotor (lb)

$\theta_{\mathrm{IBC}}: \quad$ IBC equivalent blade pitch (deg.)

$\sigma: \quad$ Solidity of the rotor 
$\phi: \quad$ Control phase angle of IBC (deg.)

$\psi$ : $\quad$ Azimuth angle (deg.).

\section{Data Availability}

The data used to support the findings of this study are included within the article.

\section{Disclosure}

This paper was presented at the 44th European Rotorcraft Forum, Delft, the Netherlands, September 18-21, 2018.

\section{Conflicts of Interest}

The authors declare that there is no conflict of interest regarding the publication of this paper.

\section{Acknowledgments}

This research was supported by Basic Science Research Program through the National Research Foundation of Korea (NRF) funded by the Ministry of Science, ICT and Future Planning (NRF-2016R1C1B1007199). This work was supported by the research fund of the Korea Aerospace Research Institute. This work was conducted at the High-Speed Compound Unmanned Rotorcraft (HCUR) research laboratory with the support of the Agency for Defense Development (ADD).

\section{References}

[1] A. J. Ruddell, Advancing Blade Concept (ABC) Technology Demonstrator, U. S. Army Research and Technology Laboratories, 1981, USAAVRADCOM-TR-81-D-5.

[2] R. Blackwell and T. Millott, "Dynamics Design Characteristics of the Sikorsky X2 TechnologyTM Demonstrator Aircraft," in Proceedings of the American Helicopter Society International 64th Annual Forum Montreal, Canada, 2008.

[3] J. Zhao, M. Brigley, and R. Modarres, "S-97 Raider rotor low speed vibratory loads analysis using CFD-CSD," in Proceedings of AIAA SciTech 2019 Forum, San Diego, CA, USA, 2019.

[4] A. Bagai, "Aerodynamic design of the X2 Technology Demonstrator $^{\mathrm{TM}}$ main rotor blades," in Proceedings of the American Helicopter Society International 64th Annual Forum, Montreal, Canada, 2008.

[5] D. S. Jenney, "ABC ${ }^{\mathrm{TM}}$ aircraft development status," in Proceedings of the European Rotorcraft and Powered Lift Aircraft Forum, Bristol, UK, 1980.

[6] R. K. Goodman and T. A. Millott, "Design, development, and flight testing of the active vibration control system for the Sikorsky S-92," in Proceedings of the American Helicopter Society International 56th Annual Forum, Virginia Beach, VA, USA, 2000.

[7] D. Walsh, S. Weiner, K. Arifian et al., "High airspeed testing of the Sikorsky X2 Technology ${ }^{\mathrm{TM}}$ Demonstrator," in Proceedings of the American Helicopter Society International 67th Annual Forum, Virginia Beach, VA, USA, 2011.

[8] R. K. Wernicke and J. M. Drees, "Second harmonic control," in Proceedings of the American Helicopter Society 19th Annual Forum, Washington, DC, USA, 1963.
[9] E. R. Wood and R. W. Powers, "Practical design consideration for a flightworthy higher harmonic control system," in Proceedings of the American Helicopter Society 36th Annual Forum, Washington, DC, USA, 1980.

[10] W. R. Splettstoesser, R. Kube, U. Seelhorst et al., Higher Harmonic Control Aeroacoustic Rotor Test (HART)-Test Document and Representative Results, Institute Report IB 12995/25, German Aerospace Center (DLR), Braunschweig, 1995.

[11] M. J. Smith, J. W. Lim, B. G. van der Wall et al., “The HART II international workshop: an assessment of the state of the art in CFD/CSD prediction," CEAS Aeronautical Journal, vol. 4, no. 4, pp. 345-372, 2013.

[12] P. Richter and A. Blass, "Full scale wind tunnel investigation of an individual blade control (IBC) system for the Bo105 hingeless rotor," in Proceedings of the European Rotorcraft Forum, Como, Italy, 1993.

[13] H. Yeo, R. Jain, and B. Jayaraman, "Investigation of rotor vibratory loads of a UH-60A individual blade control system," Journal of the American Helicopter Society, vol. 61, no. 3, pp. 116, 2016.

[14] D. Schimke, U. Arnold, and R. Kube, "Individual blade root control demonstration evaluation of recent flight tests," in Proceedings of the American Helicopter Society 45th Annual Forum, Washington, DC, USA, 1998.

[15] C. Kessler, D. Fuerst, and U. Arnold, “Open loop flight test results and closed loop status of the IBC system on the $\mathrm{CH}$ 53G helicopter," in Proceedings of the American Helicopter Society 59th Annual Forum, Phoenix, AZ, USA, 2003.

[16] T. A. Millott and P. P. Friedmann, "Vibration reduction in hingeless rotors using an actively controlled trailing edge flap - implementation and time domain simulation," in 35th Structures, Structural Dynamics, and Materials Conference, Hilton Head, SC, USA, April 1994.

[17] S. R. Viswamurthy and R. Ganguli, "Optimal placement of trailing-edge flaps for helicopter vibration reduction using response surface methods," Engineering Optimization, vol. 39, no. 2, pp. 185-202, 2007.

[18] B. Roget and I. Chopra, "Wind-tunnel testing of rotor with individually controlled trailing-edge flaps for vibration reduction," Journal of Aircraft, vol. 45, no. 3, pp. 868-879, 2008.

[19] F. K. Straub, V. R. Anand, T. S. Birchette, and B. H. Lau, "Wind tunnel test of the SMART active flap rotor," Journal of the American Helicopter Society, vol. 63, no. 1, pp. 1-16, 2018.

[20] O. Dieterich, A. Rabourdin, J.-B. Maurice, and P. Konstanzer, "Blue Pulse $\mathrm{T}^{\mathrm{TM}}$ : active rotor control by trailing edge flaps at airbus helicopters," in Proceedings of the European Rotorcraft Forum, Munich, Germany, 2015.

[21] M. L. Wilbur, W. T. Yeager Jr., and M. K. Sekula, "Further examination of the vibratory loads reduction results from the NASA/Army/MIT active twist rotor test," in 58th American Helicopter Society Annual Forum, Montreal, Canada, June 2002.

[22] S. J. Massey, A. R. Kreshock, and M. K. Sekula, "Coupled CFD/CSD computation of airloads of an active-twist rotor," in 31st AIAA Applied Aerodynamics Conference, San Diego, CA, USA, June 2013.

[23] A. Bauknecht, B. Ewers, O. Schneider, and M. Raffel, "Aerodynamic results from the STAR hover test: an examination of active twist actuation," in Proceedings of the European Rotorcraft Forum, Munich, Germany, 2015. 
[24] G. Oxley, F. Nitzsche, and D. Feszty, "Smart spring control of vibration on helicopter rotor blades," Journal of Aircraft, vol. 46, no. 2, pp. 692-696, 2009.

[25] B.-Y. Min, L. N. Sankar, and O. A. Bauchau, "A CFD-CSD coupled-analysis of HART-II rotor vibration reduction using gurney flaps," Aerospace Science and Technology, vol. 48, pp. 308-321, 2016.

[26] J. O'Leary and W. Miao, "Design of higher harmonic control for the $\mathrm{ABC}^{\mathrm{TM}}$," Journal of the American Helicopter Society, vol. 27, no. 1, pp. 52-57, 1982.

[27] G. Jacobellis, F. Gandhi, and M. Floros, “A physics-based approach to trim optimization of coaxial helicopters in highspeed flight," in Proceedings of the American Helicopter Society International 71st Annual Forum, Virginia Beach, VA, USA, 2015.

[28] J. I. Go, D. H. Kim, and J.-S. Park, "Performance and vibration analyses of lift-offset helicopters," International Journal of Aerospace Engineering, vol. 2017, Article ID 1865751, 13 pages, 2017.

[29] H. Saberi and M. Khoshlahjeh, "Overview of RCAS and application to advanced rotorcraft problems," in Proceedings of the American Helicopter Society 4th Decennial Specialist's Conference on Aeromechanics, San Francisco, CA, USA, 2004.

[30] W. Johnson, CAMRAD II: Comprehensive Analytical Method of Rotorcraft Aerodynamics and Dynamics, Johnson Aeronautics, Palo alto, CA, USA, 2012.

[31] J. W. Lim, "Consideration of structural constraints in passive rotor blade design for improved performance," The Aeronautical Journal, vol. 120, no. 1232, pp. 1604-1631, 2016.

[32] W. Johnson, "Influence of lift offset on rotorcraft performance," in Proceedings of the American Helicopter Society 64th Annual Forum, San Francisco, CA, USA, 2008. 


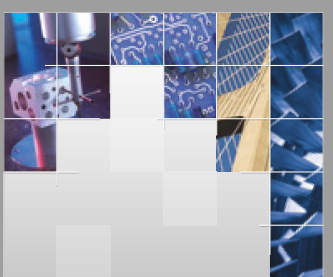

\section{Enfincering}
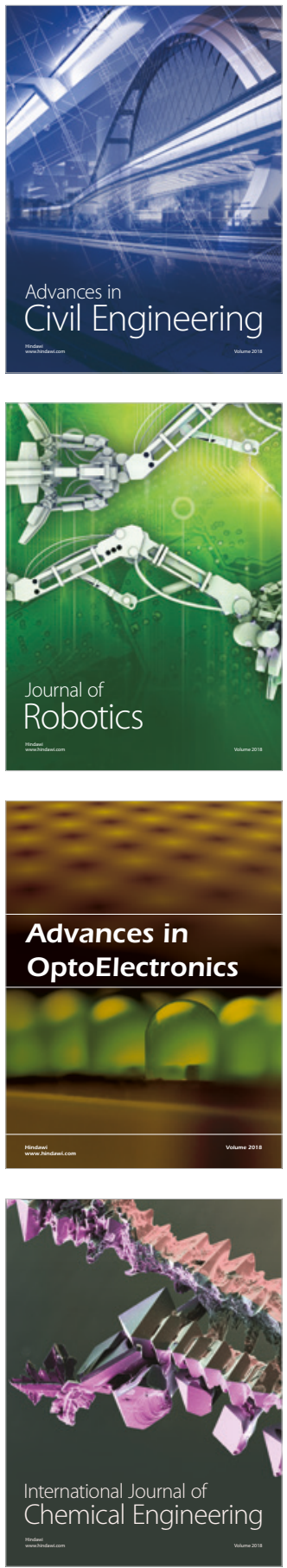

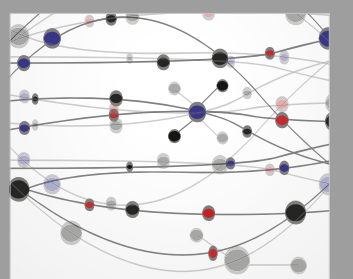

\section{Rotating \\ Machinery}

The Scientific World Journal

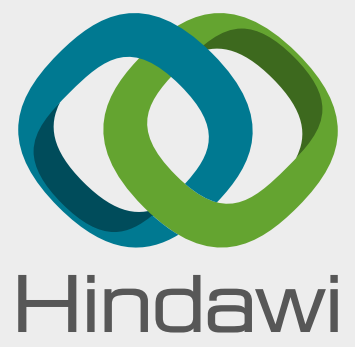

Submit your manuscripts at

www.hindawi.com
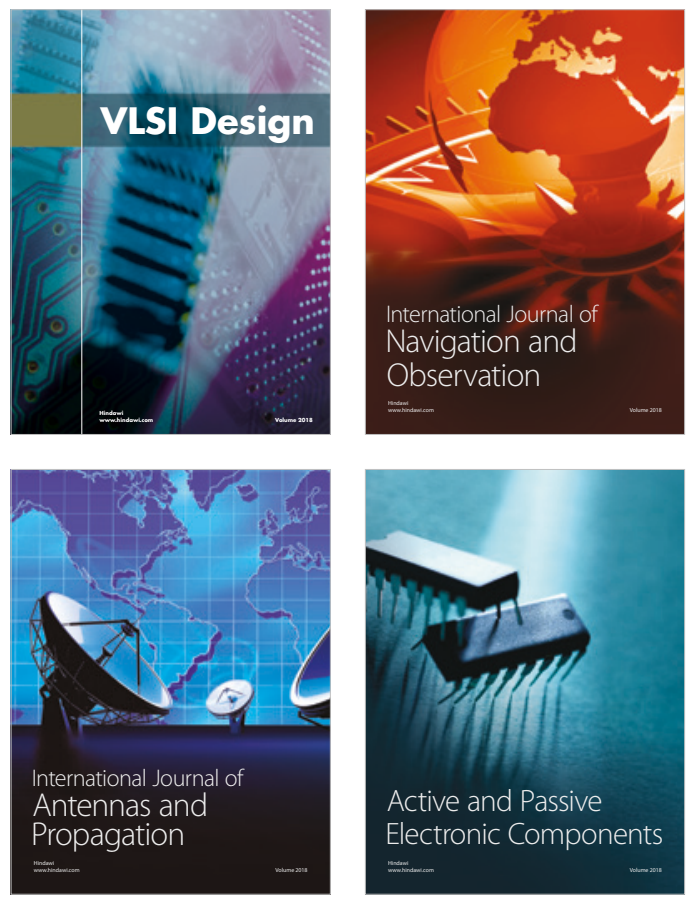
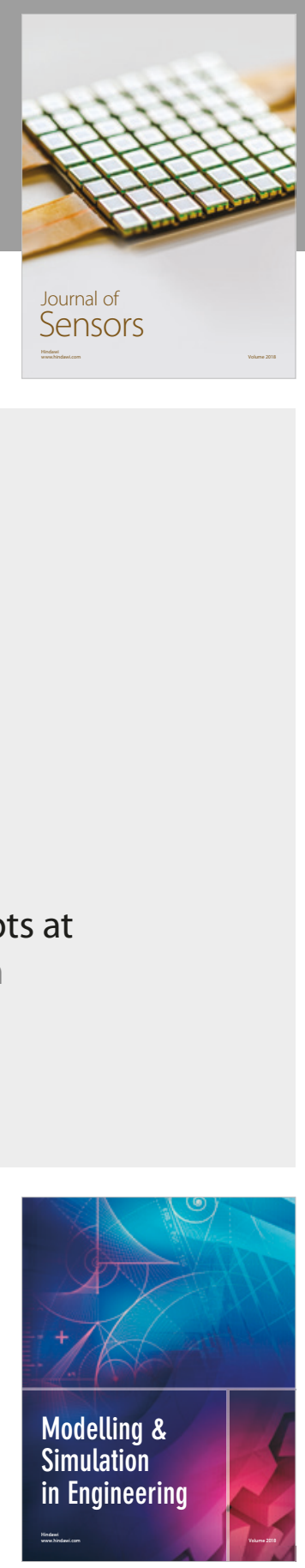

\section{Advances \\ Multimedia}
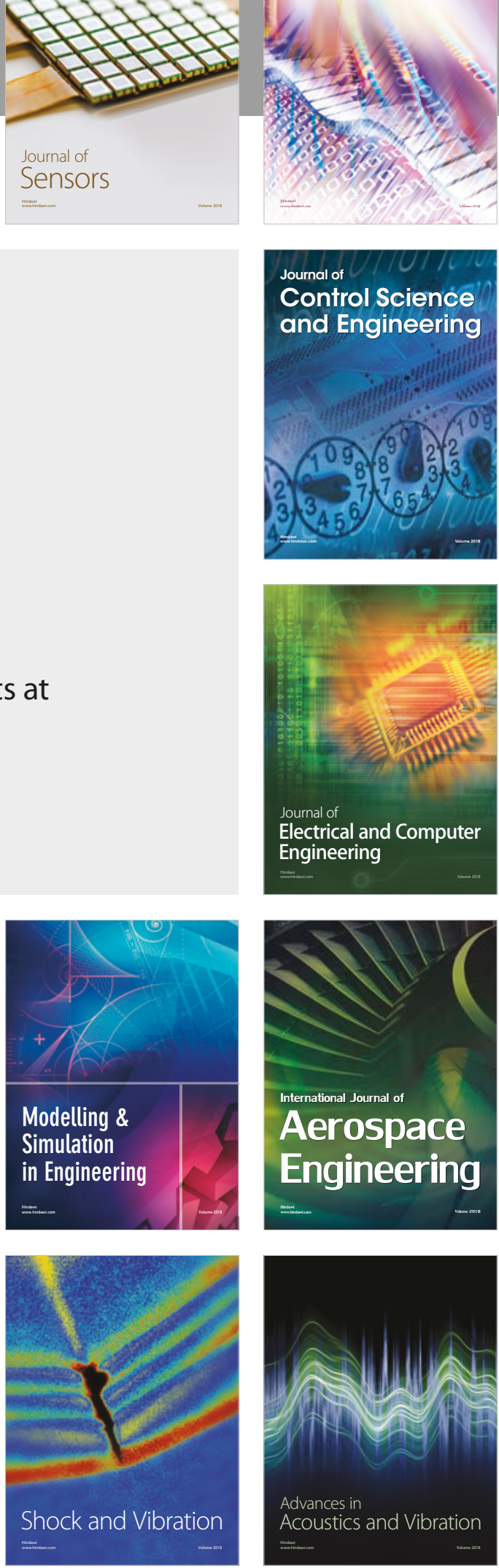